\title{
REVIEW
}

\section{Is auditory neuropathy an appropriate term? A systematic literature review on its aetiology and pathogenesis}

\author{
Neuropatia uditiva è un termine appropriato? \\ Revisione sistematica della letteratura sulla sua ezio patogenesi \\ Sandro Burdo¹, Federica Di Berardino², Gabriele Bruno ${ }^{3}$ \\ ${ }^{1}$ Scientific Coordinator of Italian Association Free to Hear; former Director of Audiovestibology Unit Varese Hospital, Varese, Italy; \\ ${ }^{2}$ Audiology Institute, Milan University, Italy; ${ }^{3}$ ENT Department, Turin University, Italy
}

\begin{abstract}
SUMMARY
To clarify the aetio-pathogenesis of Auditory Neuropathy Spectrum Disorder (ANSD), a total of 845 papers were divided into four categories: Review, Audiology, Treatment and Aetiology. Aetiology was the topic analysed categorising papers as: Genetics, Histopathology, Imaging and Medical diseases. Isolated ANs were in relation to Otoferlin, Pejvakin and DIAPH3 deficiency, and the syndromes were mainly Charcot Marie Tooth, Friedreich Ataxia, mitochondrial disorders and those associated with optic neuropathies. In histopathology papers, important information was available from analyses on human premature newborns and on some syndromic neuropathies. From cochlear dysmorphism to cerebral tumours associated with ANs, these are described in what is identified as the Imaging area. Finally, the prevalent clinical pathology was bilirubinopathy, followed by diabetes. In conclusion, AN/ANSDs do not refer to a clear pathological condition, but to an instrumental pattern without any evidence of auditory nerve involvement, except in a few conditions. The terms AN/ANSD are misleading and should be avoided, including terms such as "synaptopathy" or "dis-synchrony".
\end{abstract}

KEY WORDS: auditory neuropathy, synaptopathy, dis-synchrony, snhl, cochlear implants

\section{RIASSUNTO}

Per chiarire la ezio-patogenesi della Neuropatia Uditiva (NU), sono stati identificati 845 articoli divisi in quattro categorie: Revisioni, Audiologia, Trattamenti, Eziologia. Gli articoli sull'eziologia riguardavano: genetica, istopatologia, patologie mediche, diagnostica per immagini. La NU isolata è stata descritta nelle deficienze da otoferlina, peivachina e DIAPH3. Tra le sindromi emergono Charcot Marie Tooth, Friedreich Ataxia, i disordini mitocondriali e le neuropatie visive. Per quanto riguarda l'istopatologia chiarificanti sono stati gli articoli sui prematuri. Sia la patologia periferica che quella intracranica sono state descritte nella diagnostica per immagini. La patologia medica più frequente è risultata la bilirubinopatia, seguita dal diabete. In conclusione, la cosiddetta neuropatia uditiva non è riferibile ad una condizione patologica definita, poiché si tratta di un dato strumentale presente in una ampia serie di condizioni patologiche in cui il nervo acustico è spesso paradossalmente indenne. La revisione della letteratura porta a suggerire di abbandonare il termine di Neuropatia Uditiva perché fuorviante in molti casi.

PAROLE CHIAVE: neuropatia uditiva, dissincronia, sordità neurosensoriale, impianti cocleari

\section{Introduction}

In 1996, the term Auditory Neuropathy (AN) was proposed by Starr et al. ${ }^{1}$, describing 10 children/young people with normal cochlear outer hair cell func-
Received: July 10, 2020

Accepted: May 15, 2021

Published online: November 26, 2021

Correspondence

Sandro Burdo

Associazione Italiana Liberi di Sentire onlus

E-mail: responsabile.scientifico@liberidisentire.it

Funding

The paper was supported with a grant of Associazione Italiana Liberi di Sentire onlus (www.liberidisentire.it).

Conflict of interest

The Authors declare no conflict of interest.

How to cite this article: Burdo S, Di Berardino F, Bruno G. Is auditory neuropathy an appropriate term? A systematic literature review on its aetiology and pathogenesis. Acta Otorhinolaryngol Ital 2021;41:496-506. https://doi. org/10.14639/0392-100X-N0932

(C) Società Italiana di Otorinolaringoiatria e Chirurgia Cervico-Facciale

\section{(c) (1) $(9)$}

This is an open access article distributed in accordance with the CC-BY-NC-ND (Creative Commons Attribution-NonCommercial-NoDerivatives 4.0 International) license. The article can be used by giving appropriate credit and mentioning the license, but only for non-commercial purposes and only in the original version. For further information: https:// creativecommons.org/licenses/by-nc-nd/4.0/deed.en 
tion and abnormal auditory nerve functionality. A similar audiological framework was described by Kaga et al. ${ }^{2}$ in the same year.

The other audiological characteristics of Starr's patients were: progressive mild to moderate hearing loss, and speech discrimination poorer than expected. The impairment had become symptomatic in childhood or young adulthood, and eight patients out of 10 developed neurological neuropathy after the audiological diagnosis.

At the beginning, indeed, four audiological findings were considered the main signs of the so-called AN: normal otoacoustic emissions (OAE), unexpected absence or altered Auditory Brainstem Response (ABR), poor speech discrimination and mild to moderate hearing loss.

These signs are not different from those used in the past to identify a "retro-cochlear dysfunction", except for the OtoAcoustic-Emissions (OAE), because this is a relatively new test that was not available in the past.

From the first report in 1996 to December 2020, more than 800 papers have been written on this topic, extending the possibility of this particular kind of hearing impairment to severe to profound deafness. All degrees of impairment when the absence of or abnormal ABR is associated with the presence of OAE are called AN, without considering as pathognomonic the other two symptoms presented in the original Starr paper, which are unexpected poor speech discrimination and hearing loss not higher than moderate.

The British Association of Audiovestibular Physicians ${ }^{3}$ wrote in 2018: "Auditory neuropathy spectrum disorder (ANSD - see later) describes a condition in which a patient's outer hair cell function, as demonstrated by otoacoustic emissions (OAE) and/or cochlear microphonic $(C M)$, are (or were at one time) present, and auditory brainstem responses $(A B R)$ are abnormal or absent", without any information about the hearing loss degree.

In this way, the overlapping between the classic signs, definition of retro-cochlear dysfunction and the new AN concept disappeared.

The modification of the original description of AN, also including significant hearing loss, completely distorts the diagnostic role of ABR and Speech Audiometry since they are first altered by the hearing loss degree.

It is a common experience that click ABR cannot be elicited in the case of disabling hearing impairment starting to be absent in some patients at $65 \mathrm{~dB}$ of loss in the high frequencies and always absent in severe to profound loss, and speech discrimination is not possible without hearing devices in these degrees of hearing loss.

Due to the changes of the initial definition, it is clear that in severe to profound hearing loss the decisive instrumental sign that should confirm AN diagnosis is limited to the presence of OAE, because ABR and Speech Audiometry are not conclusive as primarily altered in all cases of significant hearing loss.

The modification of the AN description involves various audiological pathologies regarding all stations of the hearing apparatus and all degrees of hearing loss. The AN pathogenesis therefore appears to be multifactorial and the clinical results likely come from a variety of lesions throughout the auditory pathway, from inner hair cells (IHCs) to the cerebral cortex.

A group of experts ${ }^{4}$ thus decided to modify the term AN to ANSD-Auditory Neuropathy Spectrum Disorder to avoid a precise terminology being able to describe various and different dysfunctions, even if with common involvement of the $8^{\text {th }}$ nerve.

Rance and Starr ${ }^{5}$ tried to bring order to the confusing topic, limiting the so-called ANSD to 4 categories. These four categories are: 1. presynaptic disorders, affecting inner hair cells and ribbon synapses; 2 . postsynaptic disorders, affecting unmyelinated auditory nerve dendrites; 3 . postsynaptic disorders, affecting auditory ganglion cells and their myelinated axons and dendrites; 4 . central neural pathway disorders, affecting the auditory brainstem.

ANSD can be unilateral or bilateral, isolated or part of a neurologic syndrome, congenital or acquired, and producing all degrees of hearing loss.

Congenital ANSD is mainly caused by genetic abnormalities, which may be either isolated or associated with other syndromes. The inheritance pattern can include all the four main types of inheritances such as autosomal dominant, autosomal recessive, $\mathrm{X}$ - linked and mitochondrial.

An interesting summary by Santarelli ${ }^{6}$ demonstrates that the degree of loss in neurologic syndromes is almost always mild, but moderate to profound in isolated AN.

The hearing loss can be progressive, starting at childhood or adulthood especially in neurologic syndromes, but many ANs are also congenital with severe to profound hearing loss and can occur in all age groups. Even the evolution of the $\mathrm{OHC}$ function is intellectually stimulating, because in some cases the OAE disappears over time.

However, the Kaga experience regarding the evolution of congenital AN is even more interesting.

The author ${ }^{7}$ found three categories: the first can auto-resolve until normal hearing at around 12 months of life, the second evolves to severe to profound loss starting as mild and the third is part of a wider neurological syndrome.

Regarding aetiology, AN can be due to genetic disorders or can have a wide range of other aetiologies including prematurity, hyper-bilirubinaemia, anoxia, hypoxia, congenital brain anomalies and ototoxic drug exposure. Nevertheless, no aetiologic factor can be identified in approximately half of cases ${ }^{8}$. 
Regarding imaging, this is a fundamental investigation because the anatomical abnormalities of the $8^{\text {th }}$ nerve can objectively demonstrate the origin of the impairment, as in the case of hypoplasia or aplasia labelled Cochlear Nerve Deficiency (CND) ${ }^{9}$.

Hence, some criticism is presented in the literature regarding the definition of $\mathrm{AN}{ }^{10,11}$ and the observations are not merely academic, since one of the most important medical rules is that the choice of correct treatment and rehabilitation is a consequence of having knowledge of a clear pathogenesis in mind. For example, the first category defined by Race and Starr ${ }^{5}$ as pre-synaptic relates to a dysfunction of the IHCs (cochleopathy) and the hypothesised nerve dyssynchrony (neuropathy) is secondary and not a primary event.

Thus, we decided to carry out a literature review of medical evidence (genetics, histo-pathology, imaging, medical diseases) in order to obtain objective information about the aetiology and pathogenesis of AN.

\section{Materials and methods}

Literature search

A literature search was performed on PubMed, Embase, and the Cochrane Library.

The date of the last search was 31 December 2020.

To identify all relevant studies that described the results of auditory neuropathy spectrum disorders, articles were selected on the basis of the following MeSH terms and synonyms in their title, abstract, keywords, text or medical subject heading such as: "(("auditory neuropathy"[Title/ Abstract]) OR “auditory neuropathies”[Title/Abstract]) OR "Auditory neuropathy" [Supplementary Concept]).

The papers extracted from libraries were uploaded to a spreadsheet column, one per cell in the first column. The second column reported the decision to consider each paper eligible or not for the study, following the criteria described below. Finally, the third column had a drop-down menu with seven categories to choose from in order to identify the main topic of the individual paper. The categories were: Review, Audiology, Treatment, Medical aetiology, Genetics, Histopathology and Imaging. The main topic was identified by title and abstract, which was added at the end of the header of each paper. Using the spreadsheet features, we were able to obtain the seven homogenous groups to evaluate.

A total of 845 papers were extracted, but the final review was based on 799 papers disregarding those with incomplete abstracts or not available in English. For some papers, the analysis was completed by retrieving the full text when the article was considered of particular interest for the preparation of the current paper, also taking into account the reference lists.

The papers retrieved as full text are reported in the main reference list.

\section{Study selection}

The review was undertaken independently by three researchers (SB, GB and FDB), expert in critical analysis of academic literature. All the abstracts were reviewed using the predetermined inclusion, exclusion and categorisation criteria. The articles considered relevant or of uncertain relevance were retrieved as full-text papers. The full-text papers were reviewed, and data extraction performed independently by each researcher. Any discrepancies between researchers were resolved by mutual consensus. This systematic review was conducted according to the guidelines for reporting Systematic Reviews and Meta-Analysis promulgated by PRISMA ${ }^{12}$.

\section{Results}

The first publication on ANs was in 1996 and the maximum production was detected after the year 2010.

The topic mainly treated was audiology (Fig. 1), but the interest of the authors of the current paper was focused on 268 papers regarding Medical aetiology, Genetics, Histopathology and Imaging, being significant for the purpose. In other words, the papers with Audiology and Treatment as well as Review as their topic were analysed only to better understand the aetiology and pathogenesis of AN.

\section{Medical aetiology}

The most discussed medical issue related to AN was hyperbilirubinaemia, but all the pathologies are presented especially metabolic, infectious and toxic diseases (Fig. 2).

Concerning bilirubin, the auditory toxic effect starts at serum levels of $22 \mathrm{mg} / \mathrm{dl}$ and the best predictor of the hear-

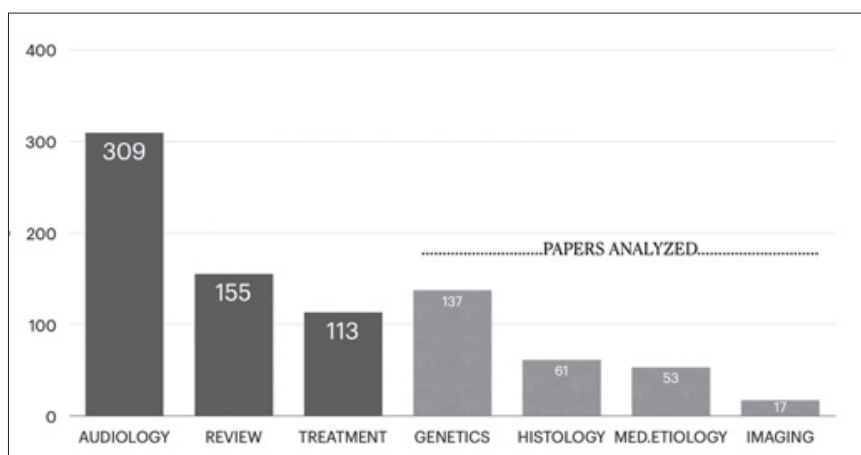

Figure 1. Main topic of the papers. 


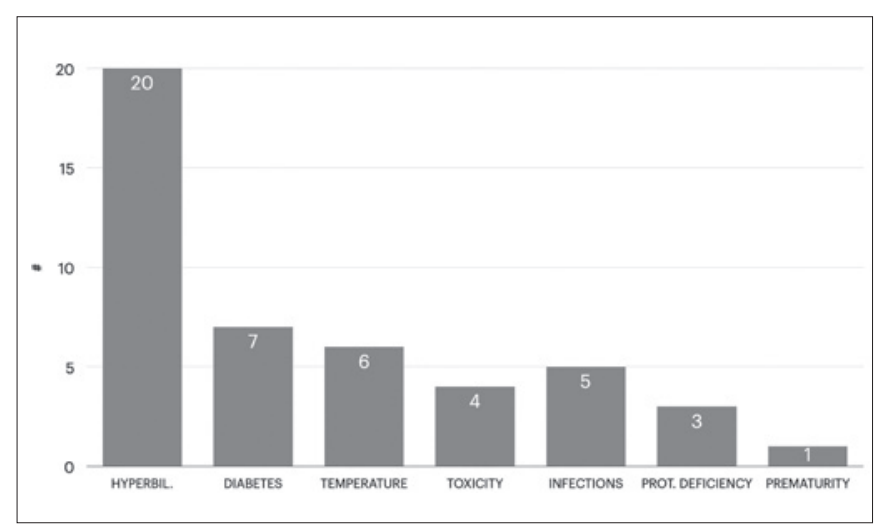

Figure 2. Medical aetiology.

ing injury is unbound bilirubin ${ }^{13}$. The percentage of hearing impairment varies widely. For example, Can et al. ${ }^{13}$ declared an incidence not more than a normal event; $11 \%$ for Amin et al. ${ }^{14}$. The data regarding the kind of hearing loss are interesting, because both SNHL and AN can result from bilirubin toxicity ${ }^{15}$. Finally, it is important to know the positive therapeutic effect on hearing loss by exchange transfusion, which worsened if ibuprofen was administered in the presence of hyperbilirubinaemia ${ }^{16}$.

On the topic of diabetes, six papers described the presence of an AN. Interestingly, but to be confirmed with additional studies, the positive effects on hearing impairment due to coffee ${ }^{17}$, glycine ${ }^{18}$, rutin ${ }^{19}$, while insulin and oral hypoglycaemic agents seemed to have no therapeutic effect ${ }^{20}$.

The ANs described after infections, among the most frequent, were those from CMV ${ }^{21}$ and parotitis ${ }^{22}$.

Some authors describe patients where symptoms only become evident with an elevation of body temperature, particularly in some cases of otoferlin mutations ${ }^{23}$.

Considering the other papers, a case report of platelet dysfunction is particularly interesting, as this was treated using adenosine triphosphate with success ${ }^{24}$, the same positive effect that can be seen with thiamine deficiency ${ }^{25}$ and biotinidase ${ }^{26}$. Other papers described the toxic effect of dioxin ${ }^{27}$, xylene ${ }^{28}$ and bismuth ${ }^{29}$.

\section{Genetics}

It is estimated that approximately $40 \%$ of AN cases have an underlying genetic basis, which can be inherited in both syndromic and non-syndromic conditions. A total of 63 papers described isolated AN and 70 described syndromic AN.

Considering isolated deafness, it is evident that the otoferlin gene mutation (autosomal recessive DFNB9) is the most frequent aetiology for the so-called AN (Fig. 3), provoking altered vesicle replenishment and delivery of IHC neurotransmitter in the ribbon synapses ${ }^{30}$.

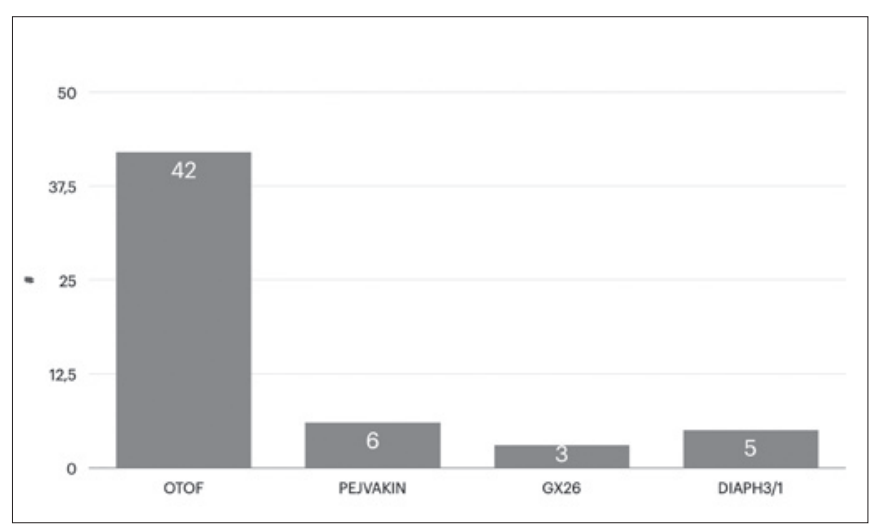

Figure 3. More frequent isolated "untrue" ANs - genetics.

The site of action of Pejvakin (autosomal recessive hearing loss - DFNB59) was initially identified in the spiral ganglion ${ }^{31}$. Today, it is clear that this protein has a role in the mechano-transduction of hair cells, involving both outer and inner hair cells ${ }^{32}$ or only IHCs.

The cochlear role of connexins (DFNB1) has been wellknown for a long time, and for DIAPH3 (AUNA1- autosomal dominant inheritance) the evolution of knowledge is similar to the Pejvakin mutation because initially a neural location was described, and today its clear role in cochlear physiology has been demonstrated ${ }^{33}$. In conclusion, all the mutations described in isolated AN involve cochlear proteins. Finally, some observations on mitochondrial mutation in non-syndromic hearing loss can be made.

While hearing loss is a common symptom, AN has only rarely been reported in these disorders. These kinds of genetic mutations can involve the cochlea in particular, as it is sensitive to energy insufficiency especially in the stria vascularis, and the predisposition to aminoglycoside-induced hearing loss ${ }^{34}$.

With regards to the papers describing syndromes, seven conditions were the subject of more than two papers, for a total of 44 (Fig. 4); the remaining 14 papers were case reports of different and rare neurologic diseases.

Interestingly, several of the genes implicated encode mitochondrial proteins, and audiograms report mild to moderate hearing loss for low frequencies ${ }^{35}$, and normal or mild hearing loss for higher ones ${ }^{4}$, as already reported by Soliman in $19877^{36}$ in the so-called "low frequencies syndrome" or "reverse slope" today. Generally, these syndromes occur phenotypically later in childhood.

The syndromes most frequently cited are: Charcot Marie Tooth (CMT) and its synonymous Hereditary Motor and Sensory Neuropathy (HMSN); Friedreich Ataxia; Mitochondrial disorders; Visual and Hearing impairment (OPA1/LEBER HON/USHER/FDXR/OPA8); Mohr TS 


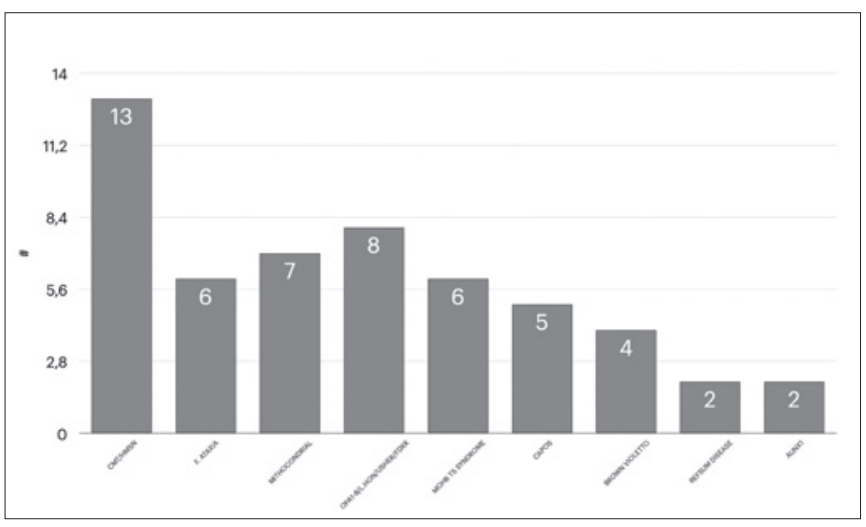

Figure 4. Most frequent syndromes.

Syndrome; Cerebellar ataxia - Areflexia - Pes cavus - Optic atrophy - Sensorineural hearing loss (CAPOS) and Brown Vialetto Syndrome.

CMT is a hereditary demyelinating or axonal ${ }^{37}$ early onset neuropathy.

In CMT, also known as HMSN, pure tone detection can be degraded from any loss to mild and severe hearing loss. In other words, the hearing abilities of people with CMT are highly variable as is the site of lesion ${ }^{38}$. Onset of symptoms is more frequent in adolescence or early adulthood. The gene most frequently mutated is MPZ, encoding a protein included in the compact myelin that plays a crucial role in myelin formation and adhesion, but most of the genes coding for proteins involved in this process have been associated with neurodegenerative diseases ${ }^{39}$.

CMT can be sensitive to corticosteroid therapy ${ }^{40}$ when symptoms are associated with infectious signs ${ }^{41}$ and hearing aid use is recommended even if the involvement of the entire auditory nerve associated with hair-cell preservation is likely to be a feature shared by the majority of AN disorders included in the CMT group ${ }^{5}$.

Hearing sensitivity can also be normal in Friedrich Ataxia syndrome, but in some cases ABR is altered ${ }^{42}$.

Mohr-Tranebjærg syndrome is a rare $\mathrm{X}$-linked recessive neurodegenerative disorder resulting in early-onset hearing impairment, gradual dystonia and optic atrophy. It can start from the very early years of childhood associated with a severe hearing loss ${ }^{43}$. CAPOS syndrome (Cerebellar ataxia, Areflexia, Pes cavus, Optic atrophy, and Sensorineural hearing loss) with acquired hearing impairment as a prominent feature ${ }^{44}$, is a rare neurological disorder associated with mutation in the ATP1A3 gene. Han et al. ${ }^{45}$ and Atilgan et al. ${ }^{46}$ described the remarkable benefits of cochlear implantation, assuming synaptophysin as the hearing loss pathogenesis.

Brown Vialetto Syndrome is a neurodegenerative disorder characterised by hearing loss and ponto-bulbar palsy due to mutations in the genes encoding the riboflavin transporters, and vitamin supplements can thus be useful.

Riboflavin therapy results in improvement of hearing thresholds during the first year of treatment in subjects with recent-onset hearing loss.

The review of Brown Vialetto Syndrome papers revealed contradictory therapeutic experiences because in some subjects the outcomes of cochlear implants were surprising ${ }^{47}$, especially if associated with riboflavin treatment ${ }^{48,49}$, but disappointing in others ${ }^{50}$.

The syndromes described above are totally disabling neurological diseases compared with diseases where the phenotype is limited to vision and hearing impairment, such as LHON and OPA1. In these pathologies, mitochondrial dysfunction is also thought to be an important pathophysiological player ${ }^{51}$.

In Leber's hereditary optic neuropathy (LHON), the degree of hearing loss varies ${ }^{52}$, but the majority of subjects have normal hearing with abnormal ABR. The evaluation of OPA1 disease is of particular interest because for some researchers the origin of hearing impairment is the dendrites of the $8^{\text {th }}$ nerve ${ }^{6}$, while for others it is the cochlea ${ }^{53}$. YuWai-Man et al. ${ }^{54}$ confirmed the phenotypical effects of the OPA1 mutation in both the inner ear and in the unmyelinated portion of the auditory nerve.

\section{Histopathology}

The papers on histopathology of ANSD consist of 57 involving animals and 7 involving humans.

The 57 papers on animals were categorised into 4 groups.

The experiments described in the first group can be considered methodological because they demonstrate how to reproduce neuronal injury/dysfunction in animals, preserving the cochlear hair cells. These papers do not add any particular new knowledge about the aetiology and pathogenesis of AN.

For the second group, the interest is more practical because they describe the mechanisms underlying drug/toxin-induced damage and above all the anatomical site of lesion/ dysfunction. IHCs are the target organ in the case of carboplatin toxicity ${ }^{55}$ and glutamate effect ${ }^{56}$ even if in contradiction with Liu et al. ${ }^{57}$ who described SGN (Spiral Ganglion Neurons) involvement. SGN is also the target of Diphtheria toxin ${ }^{58}$. Cobalt and chromium are toxic to all sensory cochlear cells ${ }^{59}$. The same consequence was described in the case of hypoxia, but with a different effect on the two sensory cells with higher vulnerability of IHCs, as hypoxia damage is related to its duration ${ }^{60}$. Bilirubin toxicity has SGN as its target for Sun et al. ${ }^{61}$, but also IHC synapses for Salvi et al. ${ }^{62}$ depending on the dosage ${ }^{63}$. Moreover, bilirubin did not reveal any auditory nerve involvement in the 
Gunn rat, but a cochlear toxicity in contradiction with the findings of Uziel et al. ${ }^{64}$ who described a preserved cochlea in the case of bilirubin toxicity in the Gunn rat. In Hidden Hearing Loss, the pathogenesis was identified in axonal fibres ${ }^{65}$. Axonal fibres were also the target of pyridoxine ${ }^{66}$ and spectrin ${ }^{67}$.

Thus, it is interesting to point out the different levels of vulnerability of $\mathrm{OHC} v s$ IHC vs nerve considering duration and/or dosages of the same toxic agents or protein deficiency.

The third group is similar to the previous one, also taking into account some genetic mutations of proteins which occur in the cochlea. All the papers describe cochlear proteins located mainly in IHCs except for Pejvakin, which was also identified in OHCs and Cx 29 originally located in SGN in another paper ${ }^{68}$. A multiple site of lesion was the effect of the abnormal expression of AIFM1 (AIF) even if with a SGN prevalence ${ }^{69}$.

The last group of papers on animals analyse possible therapies for neuronal injuries. Mesenchymal stem cells ${ }^{70}$, transcription factor Sox $2^{71}$; photo-biomodulation ${ }^{72}$; cell transplantation ${ }^{73}$; taurine ${ }^{74}$; coffee or trigonelline in pyridoxine intoxication ${ }^{75}$.

There were only seven studies performed on humans, and two of these involved both animals and humans.

Diaz-Horta ${ }^{76}$ described an interesting case of AN due to mutation of the gene ROR1 in mice because the hearing loss with preserved OAE was found in malformed cochlea (smaller and under-coiled). Less evident regarding the precise site of lesion is the experience described by AmatiBonneau et al. ${ }^{77}$ because the R445H mutation in OPA1 does not exclude inner hair cell involvement in the guinea pig, leaving the doubt of a cochleopathy and not of isolated neuropathy. On the other hand, in MPZ gene mutations, the inner hair cells were normal in number, preserving morphology and the anatomical alterations evident along the auditory nerve fibres ${ }^{78}$.

The paper by Amatuzzi et al. ${ }^{79}$ is one of the most important clinical contributions because it demonstrates that the socalled AN of premature infants is indeed a cochlear pathology. Conversely, the AN of the Mohr-Tranebjaerg syndrome, an $\mathrm{X}$-linked hearing loss caused by mitochondrial dysfunction, is due to a degeneration of spiral ganglion cells preserving the cochlear organs ${ }^{80}$. The Pejvakin distribution was also identified in human spiral ganglion ${ }^{31}$ in contrast with Harris et al. ${ }^{81}$ who located the protein inside the cochlea.

\section{Imaging}

Imaging represents the most important clinical tool to identify an AN on an anatomical basis and its execution is thus mandatory for a correct diagnosis ${ }^{82}$. We found 18 papers on imaging and $\mathrm{AN}$ : 10 described a CND, 2 a dysmorphism involving both the cochlea and the $8^{\text {th }}$ nerve, 3 intracranial tumours excluding the $8^{\text {th }}$ nerve, 1 an intracranial haemorrhage and 2 intracranial hypertension.

The papers confirmed that the hearing impairment of some ANs does not involve the 8th nerve, but is actually located in the CNS, leaving the first neuron of the auditory apparatus free from lesions.

\section{Discussion}

The first and most impressive evidence from this ANSD literature review is the fact that many dysmorphisms, dysfunctions or pathologies of all the organs of the hearing apparatus can present the pathognomonic audiological combination of "OAE present and ABR absent or altered". However, in the majority of cases the site of the lesion is the cochlea or the central nervous system and not the acoustic nerve, in contrast with the nomenclature of neuropathy.

The correct and definite attribution to the $8^{\text {th }}$ nerve as the pathogenesis of hearing impairment can be made only when it is shown by imaging evidence or when electrophysiological tests are altered in normal or mildly impaired hearing, thus when the hearing loss is not the primary origin of the alteration of the acoustic potentials. Berlin et al. ${ }^{10}$ summarised the literature on the clinical meaning of pure tone audiometry, attributing impairment to IHC dysfunction/lack/ pathology in the case of profound hearing loss.

Regarding imaging, the prevalence of retro-cochlear dysmorphism varies between $18 \%$ and $28 \%$ of AN children, frequently associated with brain $(40 \%)$ or cochlear abnormalities (31\%), especially in the case of bilateral CND ${ }^{82}$.

Both imaging and acoustic potential alterations not justified by the degree of hearing loss are the only findings that are able to reliably confirm a neuropathy; other tools or clinical observations cannot be definitive due to the wide variety of pathologies involved.

In fact, the introduction of the concept of "spectrum disorder" confirms the observation that a large number of diseases are involved in AN, but this cannot be passively accepted because in the majority of cases, since in isolated hearing loss nerve involvement is excluded due to mutations of proteins with a well-known role in the cochlea such as otoferlin, pejvakin, DIAPH3 and GJB2.

The cochlea and not the nerve is the site of dysfunction in isolated genetic ANs.

Only in neurologic syndromes for poly-neuropathies and/ or Central Nervous System disease can the cochlea be excluded as the origin of the hearing impairment, but can one be sure that the nerve is the cause of the communication difficulties of the patient and not a CNS disease? 
Concerning medical aetiology, Amatuzzi et al. ${ }^{79}$ showed that the cochlea injury is the origin of hearing loss in premature infants and not the auditory nerve. Furthermore, diabetes and hyperbilirubinaemia are identified as the most frequent aetiologies. In diabetes, the vascular side effect ${ }^{83}$ is assumed to be the pathogen in the cochlea as in the retina. More difficult to interpret is the pathogenesis of hearing loss in hyperbilirubinaemia. Some authors have described a toxic effect on neural structures, but it must be noted that the most frequent pathology in neonates starts with severe haemolytic anaemia and related hypoxia, which might be the cause of a cochleopathy ${ }^{\mathbf{8 4}}$, while motor dysfunction and dysarthria can be easily related to central toxic effect of bilirubin. Anaemia related to secondary kernicterus is not described in papers with Gunn rat protagonists ${ }^{64}$ because in that animal hyperbilirubinaemia is primary and the cochlea seems to be preserved, but not for other authors like Salvi et al. ${ }^{62}$. The reason for the contradiction about the greater or lesser involvement of the cochlea by bilirubin toxicity can be related to the evidence that the injuries are dose-dependent ${ }^{85}$. Another interesting hypothesis was that proposed by James et al. ${ }^{86}$ because they consider riboflavin depletion secondary to hyper-bilirubinaemia as a cause of hearing impairment. From these considerations, it is plausible to consider pathologies related to hyperbilirubinaemia as a spectrum disorder with greater or lesser involvement of some neural organs ${ }^{87}$, but including the possibility of a cochleopathy which is dose-dependent or caused by haemolytic anaemia or by different causes. In any case, some excellent outcomes with CIs can be used as ex juvantibus criterium to confirm the cochlea as the site of the lesion.

In summary, the term $\mathrm{AN}$ is the cause of confusion rather than the explanation of a particular framework because in most cases it is not related with the real pathogenesis of hearing impairment as evident in genetic isolated $\mathrm{AN}$ and in the main medical pathologies.

We think that the confused opinions about so-called AN could have some historical reasons and could even be related to the innovative knowledge regarding cochlea physiology (old passive scheme vs new active one). Furthermore, the confusion could originate also from the almost contemporary introduction of systems to record Oto-Emissions in the clinical field that do not always seem to be interpreted with the new scheme in mind.

Generally, the lag time between a new medical discovery and the concrete comprehension or utilisation of the new concepts is between 10 and 17 years ${ }^{88}$.

This is not the case of comprehension of the source of OAE, limited to the OHCs.

The introduction of the first commercial device to record OAE by otodynamics was in 1988 and the first complete description of the active function of OHCs was made by Brownell in $1985^{89}$, even if the idea of a cochlear amplifier had already been described by Gold in 1948 and Kemp 90 confirmed the presence of the amplifier in 1978, though with some doubts as he wrote, “...probably located in the cochlea..." explaining the new phenomenon observed.

The very short lag time between the two facts (phenomenon discovery and clinical application) led to the belief that the clinical instrument was a system to evaluate the entire cochlea and not only the $\mathrm{OHCs}$, considered as classic receptors as in the past, and thus similar to the IHCs.

It may be useful to remember that if we consider the entire cochlea as a passive organ, we should simply assume that $\mathrm{OHCs}$ and IHCs are similar as hearing receptors except for analysis of sound intensities less than around $50 \mathrm{~dB}$ for $\mathrm{OHCs}$ and louder for IHCs. Consequently, OHCs should be first considered in the case of mild hearing loss and always disrupted in the case of severe to profound hearing loss together with the IHCs in this case.

In reality, it is correct to blame $\mathrm{OHCs}$ in the case of some peripheral hearing loss up to $50 \mathrm{~dB}$ due to a lack of IHC tuning, but the same inference is not true in severe to profound hearing loss because the OHCs are not hearing cells. Thus, the possibility of finding normal OHCs in the case of a cochlear severe-to-profound hearing loss is correct.

Dallos ${ }^{91}$ wrote "Mammals hear with their IHCs - the true sensory receptors of the cochlea".

Coming back to the definitions of $\mathrm{AN}$, we think that at the beginning some authors considered otoacoustic emission devices as systems that allow evaluation of the entire cochlea, wrongly inferring that IHCs are preserved in the case of normal OHCs, because otoemissions were present. There is some important evidence, physiological as well as pathological, that can confirm the two hair cells are different organs with different functions and behaviours in the case of an ear pathology or dysfunction.

This relates to the following:

- dysfunctions on a genetic basis involving some proteins, which affect functions of one hair cell and not the other (see otoferlin for example);

- the histopathological findings in premature infants with hearing impairment due to loss of IHCs and not of $\mathrm{OHCs}^{79}$;

- the existence of deaf mice due to lack of IHCs and normal OHCs, such as the Bronx waltzer mouse ${ }^{92}$ and the Beethoven mouse ${ }^{93}$;

- the ototoxic effect of some anti-tumour drugs ${ }^{94}$ limited to the IHCs and not to the OHCs, such as carboplatin and vice versa for other drugs such as aminoglycosides ${ }^{95}$;

- different levels of vulnerability between the two hair cells 96 ; 
- different effects of some pathogens limited to IHCs or also involving $\mathrm{OHCs}$ on the basis of duration and intensity ${ }^{63}$.

\section{Conclusions}

Precise terminology in biology is a fundamental issue. According to Rapin and Gravel ${ }^{14}$, the term neuropathy does not apply to cases where hearing loss is attributable to a disease of the central auditory pathway alone, like Rance and Starr's group $4{ }^{5}$, because central tracts in the white matter of the brain, cerebellum, brainstem and spinal cord are not "nerves," and their pathologies are not "neuropathies."

Conversely, Race and Starr's group 1 consists of "cochlear hearing loss" excluding nerve involvement or other neurological pathologies.

Real neuropathies are CNDs and, probably some ADOA+ due to mutation of the OPA1 gene and other genetic hearing impairments associated with optic nerve pathologies.

In otological clinical practice, it is important to identify the precise site of the lesion for disabling hearing loss since Cochlear Implants (CIs) are contra-indicated in retro-cochlear dysfunctions and the term neuropathy implies the involvement of the auditory nerve. CIs should therefore be contraindicated in the case of the so-called ANs, although the results in clinical practice suggest the opposite in the majority of cases, especially in isolated AN.

The reason for this contradiction is simple: we are talking about cochleopathies and not neuropathies as the literature review has confirmed.

Not considering the misleading attribution to the nerve of some untrue ANs, it could lead many clinicians to feel that implantation should be indicated for all AN patients, even when hearing sensitivity is better than the usual indication ${ }^{4}$. Theoretically speaking, extending the indications for CIs from isolated genetic ANs to syndromic ANs should be considered a disputable inference: we are comparing two different kinds of disease with only two similar instrumental findings in common (OAE and ABR). The CIs outcomes in AN syndromic patients have been described as satisfying in some papers ${ }^{97}$ and inadequate in others ${ }^{98}$. This unexplained contradiction is probably due to a lack of knowledge about the disease itself. In this regard, we suggest considering the literature review reported herein showing that the knowledge concerning inner ear biology changed over time (see Pejvakin or DIAPH3 functions). This dramatically modified, for example, the enthusiastic conclusion of Starr et al. in $2004{ }^{99}$ regarding the therapeutic effects of $\mathrm{CI}$ in AUNA1 because the protein in question involves the cochlea and not the nerve, in contrast to what reported in papers based on the knowledge at that time.
These observations confirm the need to consider each patient individually, without following diagnostic models considered conclusive, when instead they are questionable just like the combination "OAE present and ABR absent" in case of severe and profound deafness.

In conclusion, we believe it is more appropriate to abandon the term Auditory Neuropathy when OAEs are present and ABR is altered or absent because it is misleading. Moreover, in case of genetic isolated AN, the terms "synaptopathy" and "dis-synchrony" are also confusing, because they do not describe the causes but the consequences of a receptor dysfunction, i.e. the production or delivery of its neurotransmitter that is a IHCs "job", with a secondary and not a primary involvement of nerve dendrites.

For all the reasons above, we suggest to not consider OAEs as pathognomonic for diagnosis of AN, if not confirmed by other signs.

Our final proposal is to consider more appropriate to include the $\mathrm{OHC}$ conditions in an overall diagnosis, using the following formula: "Hearing impairment due to (cochlear) neural/central) dysfunction, with preserved $\mathrm{OHC}$ function”, as already mentioned by Gibson ${ }^{100}$.

\section{References}

1 Starr A, Picton TW, Sininger Y. Auditory neuropathy. Brain 1996;119:741-753. https://doi.org/10.1093/brain/119.3.741

2 Kaga K, Nakamura M, Shinogami M. Auditory nerve disease of both ears revealed by auditory brainstem response, electrocochleography and otoacoustic emissions. Scand Audiol 1996;25:233-238. https:// doi.org/10.3109/01050399609074960

3 British Association of Audiovestibular Physicians. Guidelines for aetiological investigation into auditory neuropathy spectrum disorder in children and young adults. 2018 July. https://www.baap.org.uk/ uploads/1/1/9/7/119752718/guidelines_for_ansd_final_version.pdf

4 Guidelines for identification and management of infants and young children with auditory neuropathy spectrum disorder. The Children's Hospital Colorado, 2008 https://www.childrenscolorado.org/ globalassets/departments/ear-nose-throat/ansd-monograph.pdf

5 Rance G, Starr A. Pathophysiological mechanisms and functional hearing consequences of auditory neuropathy. Brain 2015;138:31413158. https://doi.org/10.1093/brain/awv270

6 Santarelli R. Information from cochlear potentials and genetic mutations helps localize the lesion site in auditory neuropathy. Genome Med 2010;2:91. https://doi.org/10.1186/gm212

7 Kaga K. Auditory nerve disease and auditory neuropathy spectrum disorders. Auris Nasus Larynx 2016;43:10-20. https://doi. org/10.1016/j.anl.2015.06.008

8 Starr A. Auditory neuropathy and inner hair cell and synapses. Zhonghua Er Bi Yan Hou Tou Jing Wai Ke Za Zhi 2008;43:323-326.

9 Levi J, Ames J, Bacik K. Clinical characteristics of children with cochlear nerve dysplasias. Laryngoscope 2013;123:752-756. https:// doi.org/10.1002/lary.23636

10 Gibson WP, Graham JM. Auditory neuropathy' and cochlear implantation - myths and facts. Cochlear Implants Int 2008;9:1-7. https://doi. org/10.1179/cim.2008.9.1.1 
11 Rapin I, Gravel GS. Auditory neuropathy: a biologically inappropriate label unless acoustic nerve involvement is documented. J Am Acad Audiol 2006;17:147-150. https://doi.org/10.3766/jaaa.17.2.7

12 Moher D, Liberati A, Tetzlaff J, et al. The PRISMA Group preferred reporting items for systematic reviews and meta-analyses: the PRISMA Statement. PLoS Med 2009;6:e1000097. https://doi.org/10.1371/ journal.pmed.1000097

13 Can E, Verim A, Başer E. Auditory neuropathy in late preterm infants treated with phototherapy for hyperbilirubinemia. Int J Audiol 2015;54:89-95. https://doi.org/10.3109/14992027.2014.938779

14 Amin SB, Wang H, Laroia N. Unbound bilirubin and auditory neuropathy spectrum disorder in late preterm and term infants with severe jaundice. J Pediatr 2016;173:84-89. https://doi.org/10.1016/j. jpeds.2016.02.024

15 Amin SB, Saluja S, Saili A, et al. Chronic auditory toxicity in late preterm and term infants with significant hyperbilirubinemia. Pediatrics 2017;140:e20164009. https://doi.org/10.1542/peds.2016-4009

16 Gal P, Ransom JL, Davis SA. Possible ibuprofen-induced kernicterus in a near-term infant with moderate hyperbilirubinemia. J Pediatr Pharmacol Ther 2006;11:245-250. https://doi. org/10.5863/1551-6776-11.4.245

17 Hong BN, Yi TH, Park R. Coffee improves auditory neuropathy in diabetic mice. Neurosci Lett 2008;441:302-306. https://doi. org/10.1016/j.neulet.2008.06.049

18 Muñoz-Carlin MdL, Rodríguez-Moctezuma JR, Gómez Latorre JG. Effects of glycine on auditory evoked potentials among diabetic patients with auditory pathway neuropathy. Rev Med Chil 2010;138:1246-1252. https://doi.org/S0034-98872010001100006

19 Doostkam A, Mirkhani H, Iravani K, et al. Effect of rutin on diabetic auditory neuropathy in an experimental rat model. Clin Exp Otorhinolaryngol 2021;14:259-267. https://doi.org/10.21053/ceo.2019.02068

20 Asma A, Azmi MN, Mazita A. A single blinded randomized controlled study of the effect of conventional oral hypoglycemic agents versus intensive short-term insulin therapy on pure tone audiometry in type II diabetes mellitus. Indian J Otolaryngol Head Neck Surg 2011;63:114-118. https://doi.org/10.1007/s12070-011-0132-y

21 Natale F, De Curtis M, Bizzarri B, et al. Isolated auditory neuropathy at birth in congenital cytomegalovirus infection. Ital J Pediatr 2020;46:3. https://doi.org/10.1186/s13052-019-0767-y

22 Salvinelli F, Firrisi L, Greco F. Preserved otoacoustic emissions in postparotitis profound unilateral hearing loss: a case report. Ann Otol Rhinol Laryngol 2004;113:887-890. https://doi. org/10.1177/000348940411301107

23 Marlin S, Feldmann D, Nguyen Y. Temperature-sensitive auditory neuropathy associated with an otoferlin mutation: deafening fever! Biochem Biophys Res Commun 2010;394:737-742. http://doi. org/10.1016/j.bbrc.2010.03.062

24 Nobutoki T, Sasaki M, Fukumizu M. Fluctuating hearing loss, episodic headache, and stroke with platelet hyperaggregability: coexistence of auditory neuropathy and cochlear hearing loss. Brain Dev 2006;28:55-59. https://doi.org/10.1016/j.braindev.2005.03.012

25 Attias J, Raveh E, Aizer-Dannon A. Auditory system dysfunction due to infantile thiamine deficiency: long-term auditory sequelae. Audiol Neurootol 2012;17:309-320. https://doi.org/10.1159/000339356

26 Talebi H, Yaghini O. Auditory neuropathy/dyssynchrony in biotinidase deficiency. J Audiol Otol 2016;20:53-54. https://doi.org/10.7874/ jao.2016.20.1.53

27 Safe TM, Luebke AE. Prenatal low dosage dioxin (TCDD) exposure impairs cochlear function resulting in auditory neuropathy. Hear Res 2016;331:7-12. https://doi.org/10.1016/j.heares.2015.09.015
28 Draper TH, Bamiou DE. Auditory neuropathy in a patient exposed to xylene: case report. J Laryngol Otol 2009;123:462-465. https://doi. org/10.1017/S0022215108002399

29 Siram R, Botta R, Kashikunte C. Chronic encephalopathy with ataxia, myoclonus, and auditory neuropathy: a case of bismuth poisoning. Neurol India 2017;65:186-187. https://doi. org/10.4103/0028-3886.198185

30 Moser T, Starr A. Auditory neuropathy - neural and synaptic mechanisms. Nat Rev Neurol 2016;12:135-149. https://doi.org/10.1038/ nrneurol.2016.10

31 Liu W, Kinnefors A, Boström M. Distribution of pejvakin in human spiral ganglion: an immunohistochemical study. Cochlear Implants Int 2013;14:225-231. https://doi.org/10.1179/1754762812Y.0000000027

32 Ebermann I, Walger M, Scholl HP. Truncating mutation of the DFNB59 gene causes cochlear hearing impairment and central vestibular dysfunction. Hum Mutat 2007;28:571-577. https://doi. org/10.1002/humu.20478

33 Surel C, Guillet M, Lenoir M. Remodeling of the inner hair cell microtubule meshwork in a mouse model of auditory neuropathy AUNA1. eNeuro 2016; 29:3:ENEURO.0295-16.2016. https://doi.org/10.1523/ ENEURO.0295-16.2016

34 Fischel-Ghodsian N. Mitochondrial deafness. Ear Hear 2003;24:303313. https://doi.org/10.1097/01.AUD.0000079802.82344.B5

35 Wang H, Bing D, Li J, et al. High frequency of AIFM1 variants and phenotype progression of auditory neuropathy in a Chinese population. Neural Plast 2020;2020:5625768. https://doi. org/10.1155/2020/5625768

36 Soliman SM. Low-frequency sensorineural hearing loss: a syndrome. Audiology 1987;26:332-338. https://doi. org/10.3109/00206098709081560

37 Hattori N, Yamamoto M, Yoshihara T. Demyelinating and axonal features of Charcot-Marie-Tooth disease with mutations of myelinrelated proteins (PMP22, MPZ and Cx32): a clinicopathological study of 205 Japanese patients. Brain 2003;126:134-151. https://doi. org/10.1093/brain/awg012

38 Giuliani N, Holte L, Shy M, et al. The audiologic profile of patients with Charcot-Marie Tooth neuropathy can be characterised by both cochlear and neural deficits. Int J Audiol 2019;58:902-912. https:// doi.org/10.1080/14992027.2019.1633022

39 Lerat J, Magdelaine C, Roux AF, et al. Hearing loss in inherited peripheral neuropathies: molecular diagnosis by NGS in a French series. Mol Genet Genomic Med 2019;7:e839. https://doi.org/10.1002/ mgg3.839

40 Maeda Y, Kataoka Y, Sugaya A. Steroid-dependent sensorineural hearing loss in a patient with Charcot-Marie-Tooth disease showing auditory neuropathy. Auris Nasus Larynx 2015;42:249-253. https:// doi.org/10.1016/j.anl.2014.11.002

41 Ginsberg L, Malik O, Kenton AR. Coexistent hereditary and inflammatory neuropathy. Brain 2004;127:193-202. https://doi.org/10.1093/ brain/awh017

42 Rance G, Fava R, Baldock H. Speech perception ability in individuals with Friedreich ataxia. Brain 2008b;131:2002-2012. https://doi. org/10.1093/brain/awn104

43 Huang YY, Yang J. One case report of Mohr-Tranebjærg syndrome. Lin Chung Er Bi Yan Hou Tou Jing Wai Ke Za Zhi 2019;33:848-849. https://doi.org/10.13201/j.issn.1001-1781.2019.09.012

44 Paquay S, Wiame E, Deggouj N. Childhood hearing loss is a key feature of CAPOS syndrome: a case report. Int J Pediatr Otorhinolaryngol 2018;104:191-194. https://doi.org/10.1016/j.ijporl.2017.11.022

45 Han KH, Oh DY, Lee S. ATP1A3 mutations can cause progressive auditory neuropathy: a new gene of auditory synaptopathy. Sci Rep 2017;7:16504. https://doi.org/10.1038/s41598-017-16676-9 
46 Atilgan A, Yuksel M, Ciprut A. Cochlear implantation in a case of auditory neuropathy spectrum disorder with CAPOS syndrome. Medeni Med J 2019;34:318-323. https://doi.org/10.5222/MMJ.2019.53503

47 Anderson P, Schaefer S, Henderson L. Cochlear implantation in children with auditory neuropathy: lessons from Brown-VialettoVan Laere syndrome. Cochlear Implants Int 2019;20:31-38. https:// doi.org/10.1080/14670100.2018.1534035

48 Mutlu B, Topçu MT, Çiprut A. A case with Brown-Vialetto-Van Laere syndrome: a sudden onset auditory neuropathy spectrum disorder. Turk Arch Otorhinolaryngol 2019;57:201-205. https://doi. org/10.5152/tao.2019.4639

49 Chaya S, Zampoli M, Gray D. The first case of riboflavin transporter deficiency in sub-Saharan Africa. Semin Pediatr Neurol 2018;26:1014. https://doi.org/10.1016/j.spen.2017.03.002

50 Sinnathuray AR, Watson DR, Fruhstorfer B. Cochlear implantation in Brown-Vialetto-Van-Laere syndrome. J Laryngol Otol 2011;125:314317. https://doi.org/10.1017/S0022215110001982

51 Yu-Wai-Man P, Griffiths PG, Chinnery PF. Mitochondrial optic neuropathies - Disease mechanisms and therapeutic strategies. Prog Retin Eye Res 2011;30:81-114. https://doi.org/10.1016/j. preteyeres.2010.11.002

52 Ceranić B, Luxon LM. Progressive auditory neuropathy in patients with Leber's hereditary optic neuropathy. J Neurol Neurosurg Psychiatry 2004;75:626-630. https://doi.org/10.1136/jnnp.2003.017673

53 Kullar PJ, Quail J, Lindsey P. Both mitochondrial DNA and mitonuclear gene mutations cause hearing loss through cochlear dysfunction. Brain 2016;139:e33. https://doi.org/10.1093/brain/aww051

54 Yu-Wai-Man P, Chinnery PF. Reply: Sensorineural hearing loss in OPA1-linked disorders. Brain 2013;136:e237. https://doi.org/10.1093/ brain/aws341

55 Matsumoto M, Sekiya T, Kojima K. An animal experimental model of auditory neuropathy induced in rats by auditory nerve compression. Exp Neurol 2008;210:248-256. https://doi.org/10.1016/j. expneurol.2007.11.006

56 Qing $\mathrm{S}$, Jian-he $\mathrm{S}, \mathrm{Xi}$-zheng $\mathrm{S}$, et al. Effects of glutamate on distortion product otoacoustic emissions and auditory brainstem responses in guinea pigs. J Otol 2008;3:29-34. https://doi.org/10.1016/ S1672-2930(08)50005-5

57 Liu HJ, Wang J, Dong MM. Observation of auditory brainstem response and distortion product otoacoustic emission on the animal model of autoimmune auditory neuropathy. Zhonghua Er Bi Yan Hou Tou Jing Wai Ke Za Zhi 2006;41:132-137.

58 Pan H, Song Q, Huang Y, et al. Auditory neuropathy after damage to cochlear spiral ganglion neurons in mice resulting from conditional expression of diphtheria toxin receptors. Sci Rep 2017;7:6409. https://doi.org/10.1038/s41598-017-06600-6

59 Hong BN, Yi TH, Kim SY. High-dosage pyridoxine-induced auditory neuropathy and protection with coffee in mice. Biol Pharm Bull 2009;32:597-603. https://doi.org/10.1248/bpb.32.597

60 Ye HB, Shi HB, Wang J. Bilirubin induces auditory neuropathy in neonatal guinea pigs via auditory nerve fiber damage. J Neurosci Res 2012;90:2201-2213. https://doi.org/10.1002/jnr.23107

${ }_{61}$ Sun Q, Sun JH, Shan XZ, et al. Effect of glutamate on distortion product otoacoustic emission and auditory brainstem response in guinea pigs. Zhonghua Er Bi Yan Hou Tou Jing Wai Ke Za Zhi 2005;40:435-439.

62 Salvi RJ, Wang J, Ding D. Auditory deprivation of the central auditory system resulting from selective inner hair cell loss: animal model of auditory neuropathy. Scand Audiol Suppl 1999;51:1-12.

63 Sawada S, Mori N, Mount RJ et al. Vulnerability of inner and outer hair cell systems to chronic mild hypoxia and glutamate ototox- icity: insights into the cause of auditory neuropathy. J Otolaryngol 2001;30:106-114. https://doi.org/10.2310/7070.2001.20818

64 Uziel A, Marot M, Pujol R. The Gunn rat: an experimental model for central deafness. Acta Otolaryngol 1983;95:651-656. https://doi. org/10.1016/0378-5955(91)90138-y

65 Wan G, Corfas G. Transient auditory nerve demyelination as a new mechanism for hidden hearing loss. Nat Commun 2017;8:14487. https://doi.org/10.1038/ncomms14487

66 Park C, Lim H, Moon SK, et al. Pyridoxine preferentially induces auditory neuropathy through mitochondrial dysfunction and endoplasmic reticulum stress-mediated apoptosis. Ann Otol Rhinol Laryngol 2019;128:117S-124S. https://doi.org/10.1177/0003489419836116

67 May BJ, Lauer AM, Roos MJ. Impairments of the medial olivocochlear system increase the risk of noise-induced auditory neuropathy in laboratory mice. Otol Neurotol 2011;32:1568-1578. https://doi. org/10.1097/MAO.0b013e31823389a1

68 Apostoli P, Catalani S, Zaghini A, et al. High doses of cobalt induce optic and auditory neuropathy. Exp Toxicol Pathol 2013;65:719-727. https://doi.org/10.1016/j.etp.2012.09.006

69 Zong L, Zhao J, Wu W, et al. AIF knockdown induce apoptosis and mitochondrial dysfunction in cochlear spiral ganglion neurons in vitro. Mol Med Rep 2020;21:1910-1920. https://doi.org/10.3892/ mmr.2020.10970

70 Cho YB, Cho HH, Jang S, et al. Soft neural differentiated human mesenchymal stem cells into the cochlea of an auditory-neuropathy guinea pig model. J Korean Med Sci 2011;26:492-498. https://doi. org/10.3346/jkms.2011.26.4.492

71 Lang H, Li M, Kilpatrick LA, et al. Sox2 up-regulation and glial cell proliferation following degeneration of spiral ganglion neurons in the adult mouse inner ear. J Assoc Res Otolaryngol 2011;12:151-171. https://doi.org/10.1007/s10162-010-0244-1

72 Lee MY, Bae SH, Chang SY, et al. Photobiomodulation by laser therapy rescued auditory neuropathy induced by ouabain. Neurosci Lett 2016;633:165-173. https://doi.org/10.1016/j.neulet.2016.09.039

73 Chen HC, Liang CM, Wang $\mathrm{CH}$, et al. Transplantation of human limbus-derived mesenchymal stromal cells via occipital approach improves hearing in animal auditory neuropathy. Int J Pediatr Otorhinolaryngol 2019;117:67-72. https://doi.org/10.1016/j. ijporl.2018.11.018

74 Huang X, Liu J, Wu W, et al. Taurine enhances mouse cochlear neural stem cell transplantation via the cochlear lateral wall for replacement of degenerated spiral ganglion neurons via sonic hedgehog signaling pathway. Cell Tissue Res 2019;378:49-57. https://doi.org/10.1007/ s00441-019-03018-6

75 Hong BN, Yi TH, Kim SY, et al. High-dosage pyridoxine-induced auditory neuropathy and protection with coffee in mice. Biol Pharm Bull 2009; 32:597-603. https://doi.org/10.1248/bpb.32.597

76 Diaz-Horta O, Abad C, Sennaroglu L, et al. ROR1 is essential for proper innervation of auditory hair cells and hearing in humans and mice. Proc Natl Acad Sci USA 2016;113:5993-5998. https://doi. org/10.1073/pnas.1522512113

77 Amati-Bonneau P, Guichet A, Olichon A, et al. OPA1 R445H mutation in optic atrophy associated with sensorineural deafness. Ann Neurol 2005;58:958-963. https://doi.org/10.1002/ana.20681

78 Starr A, Michalewski HJ, Zeng FG, et al. Pathology and physiology of auditory neuropathy with a novel mutation in the MPZ gene (Tyr145->Ser). Brain 2003;126:1604-1619. https://doi.org/10.1093/ brain/awg 156

79 Amatuzzi M, Liberman MC, Northrop C. Selective inner hair cell loss in prematurity: a temporal bone study of infants from a neonatal intensive care unit. J Assoc Res Otolaryngol 2011;12:595-604. https:// doi.org/10.1007/s10162-011-0273-4 
80 Bahmad FJr, Merchant SN, Nadol JBJr. Otopathology in MohrTranebjaerg syndrome. Laryngoscope 2007;117:1202-1208. https:// doi.org/10.1097/MLG.0b013e3180581944

81 Harris SL, Kazmierczak M, Pangršič T, et al. Conditional deletion of pejvakin in adult outer hair cells causes progressive hearing loss in mice. Neuroscience 2017;344:380-393. https://doi.org/10.1016/j. neuroscience.2016.12.055

82 Roche JP, Huang BY, Castillo M, et al. Imaging characteristics of children with auditory neuropathy spectrum disorder. Otol Neurotol 2010;31:780-788. https://doi.org/10.1097/mao.0b013e3181d8d528

83 Dziennis S, Reif R, Zhi Z, et al. Effects of hypoxia on cochlear blood flow in mice evaluated using Doppler optical microangiography. J Biomed Opt 2012;17:106003. https://doi.org/10.1117/1. JBO.17.10.106003

${ }_{84}$ Shirane M, Harrison RV. The effects of hypoxia on sensory cells of the cochlea in chinchilla. Scanning Microsc 1987;1:1175-1183.

85 Amato M. Mechanisms of bilirubin toxicity. Eur J Pediatr 1995;154:S54-S59. https://doi.org/10.1007/BF02191507

86 James AL, Chakraborty P, Tomlinson C, et al. Does riboflavin depletion cause auditory neuropathy spectrum disorder in at risk neonates? Int J Pediatr Otorhinolaryngol 2020;137:110238. https://doi. org/10.1016/j.ijporl.2020.110238

87 Shapiro S.M. Definition of the clinical spectrum of kernicterus and bilirubin-induced neurologic dysfunction (BIND). J Perinatol 2005;25:54-59. https://doi.org/10.1038/sj.jp.7211157

88 Hanney SR, Castle-Clarke S, Grant J, et al. How long does biomedical research take? Studying the time taken between biomedical and health research and its translation into products, policy, and practice. Health Res Policy Syst 2015;13:1. https://doi.org/10.1186/1478-4505-13-1

89 Brownell WE, Bader CR, Bertrand D, et al. Evoked mechanical responses of isolated cochlear outer hair cells. Science 1985;227:194196. https://doi.org/10.1126/science.3966153
90 Kemp DT. Stimulated acoustic emissions from within the human auditory system. J Acoust Soc Am 1978;64:1386-1391. https://doi. org/10.1121/1.382104

91 Dallos P. Cochlear neurobiology: revolutionary developments. ASHA 1988;30:50-56.

92 Bussoli TJ, Kelly A, Steel P. Localization of the Bronx waltzer (bv) deafness gene to mouse chromosome 5. Mammalian Genome 1997;10:714-717. https://doi.org/10.1007/s003359900552

93 Deol MS. The inner ear in Bronx waltzer mice. Acta Otolaryngol 1981;92:331-336. https://doi.org/10.3109/00016488109133269

94 Harrison RV. Models of auditory neuropathy based on inner hair cell damage. In: Sininger YS, Starr A, editors. Auditory neuropathy: a new perspective on hearing disorders. Albany, NY: Singular Thompson Learning; 2001. pp. 51-66.

95 Petersen L, Rogers C. Aminoglycoside-induced hearing deficits a review of cochlear ototoxicity. J South African Family Practice 2015;57:77-82. https://doi.org/10.1080/20786190.2014.1002220

96 Amarjargal N, Andreeva N, Gross J, et al. Differential vulnerability of outer and inner hair cells during and after oxygen-glucose deprivation in organotypic cultures of newborn rats. Physiol Res 2009;58:895-902.

97 Chaudhry D, Chaudhry A, Muzaffar J, et al. Implantation outcomes in post synaptic auditory neuropathies: a systematic review and narrative synthesis. J Int Adv Otol 2020;16:411-431. https://doi.org/10.5152/ iao.2020.9035

98 Rance G, Barker EJ. Speech perception in children with auditory neuropathy/dyssynchrony managed with either hearing aids or cochlear implants. Otol Neurotol 2008;29:179-182. https://doi.org/10.1097/ mao.0b013e31815e92fd

99 Starr A, Isaacson B, Michalewski HJ, et al. A dominantly inherited progressive deafness affecting distal auditory nerve and hair cells. J Assoc Res Otolaryngol 2004;5:411-426. https://doi: 10.1007/ s10162- 004-5014-5

100 Gibson WP, Sanli H. Auditory neuropathy: an update. Ear Hear 2007;28:102S-106S. https://doi.org/10.1097/AUD.0b013e3180315392 